\title{
Análisis Morfológico en el Procesamiento Óptico-Digital de Imágenes para el Diagnóstico de la Disquinesia Ciliar
}

\author{
Myriam Herrera $^{(1)}$ y Alfredo Moreno(2) \\ (1) Departamento de Ciencias, Facultad de Ingeniería, Universidad Libre de Colombia, Bogotá-Colombia. \\ (e-mail: myriam.herrerap@unilibrebog.edu.co) \\ (2) Departamento de Física, Instituto Superior Politécnico José Antonio Echeverría, La Habana-Cuba. \\ (e-mail: amore@electrica.cujae.edu.cu)
}

Recibido Jun. 14, 2013; Aceptado Ago. 9, 2013; Versión final recibida Ago. 25, 2013

\section{Resumen}

Se presenta el análisis morfológico en el procesamiento óptico digital de imágenes para caracterizar los cilios y en particular, sus componentes estructurales, asociados al movimiento ciliar. Esto se hace a partir del modelo de un corte transversal del mismo. Se desarrolla una morfología matemática con algoritmos basados en herramientas de la segmentación de imágenes, para ser aplicados a cortes transversales de cilios reales. Se estudiaron componentes estructurales tales como los microtúbulos, las dineínas, la membrana citoplasmática y las proyecciones radiales. La aplicación de procesos digitales a imágenes obtenidas por microscopía electrónica de transmisión permitió evaluar el cambio de estructuras y anormalidades de cilios de mamíferos y a partir de estos resultados metodológicos, contribuir al diagnóstico de la disquinesia ciliar en mamíferos.

Palabras clave: análisis morfológico, procesamiento óptico digital, cilios, disquinesia ciliar.

\section{Morphologic Analysis in the Optic-Digital Prosecution of Images for the Diagnosis of the Ciliary Dyskinesia}

\begin{abstract}
The morphologic analysis in the digital optic prosecution of images to characterize the cilia and in particular, its structural components, associated to the ciliary movement is presented. This is done starting from the pattern of a traverse cut of the same one. A mathematical morphology is developed with algorithms based on image segmentation tools to be applied to traverse cuts of real cilia. Structural components such as microtubes, dynein, citoplasmatic membrane and radial projections. The application of digital processes to images obtained by electronic transmission microscopy allowed evaluating the change of structures and abnormalities of cilia in mammals and starting from these methodological results to contribute to the diagnosis of ciliary dyskinesia in mammals.
\end{abstract}

Keywords: morphologic analysis, digital optic prosecution of images, cilia, ciliary dyskinesia. 


\section{INTRODUCCION}

Con el procesamiento óptico - digital de imágenes se han desarrollado diferentes algoritmos que han permitido el tratamiento de imágenes obtenidas de muestras de materiales orgánicos e inorgánicos. Estos algoritmos han permitido leer e interpretar diferentes características morfológicas y funcionales, así como realizar mediciones, transformaciones y reconstrucciones tridimensionales de los objetos estudiados utilizando lenguajes de programación. En los últimos años se ha incrementado el estudio de ramas de ciencias de la vida y la tecnología a partir de procesamiento y análisis de imágenes que han marcado el avance en la investigación. Entre estos se encuentra la investigación del ADN (Hornef, 2006) y el estudio de la estructura de los fullerenos en nanotecnología (Tabata, 2002).

Gran información de las muestras de estos campos de la ciencia está en la dimensionalidad micrométrica y nanométrica, "más de lo mismo, tal vez a otra escala" (Villaveces, 2005). Se hace necesario utilizar instrumentos ópticos, microscopios de alta resolución que permitan realizar observaciones de objetos de esas dimensiones y posteriormente diseñar procesamientos ópticos y digitales que incrementen el contraste, la nitidez y la posibilidad de aprovechar de ellas la mayor información (Alfonso, 2010). En el estudio y caracterización de muestras biológicas es ampliamente utilizada la microscopía Óptica y Electrónica, las cuales han permitido captar información de dimensiones micrométricas y nanométricas (Haugland, 1992; Pertuz, 2007).

El uso del microscopio electrónico de transmisión (TEM) ha permitido la caracterización de células y su estructura (Morán, 1987). Las partes de la célula que se han podido caracterizar por estos instrumentos son los cilios. Teknos, 1997). Son estructuras cilíndricas (figura 1) que salen de la superficie de algunas células, miden entre 5 y $7 \mu \mathrm{m}$ de longitud y son utilizados por los organismos unicelulares para impulsarse a través de líquidos y por organismos multicelulares para transportar fluidos (Barrett, 2010).

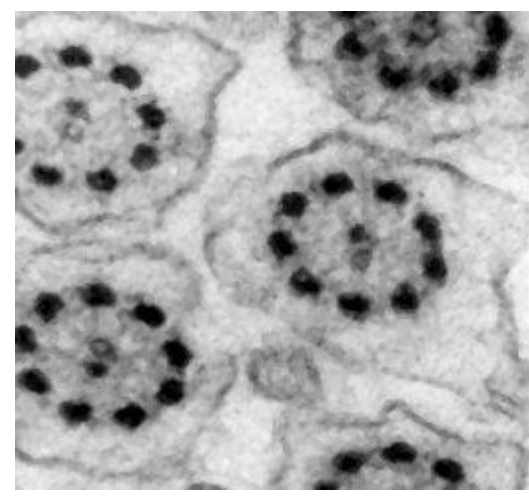

a)

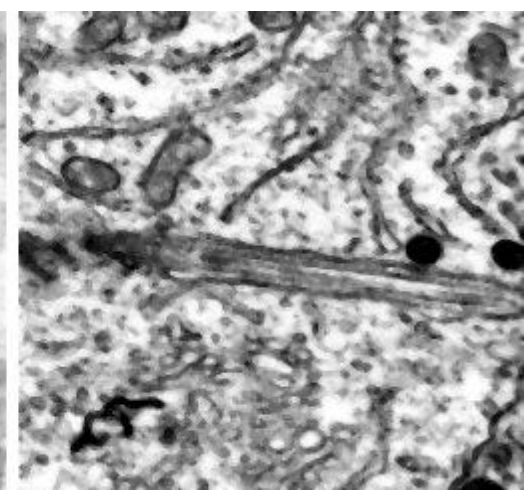

b)

Fig.1: Imagen de cortes (a) transversales y (b) longitudinales de cilios. (www1.unex.es/.../especialimembrana.htm)

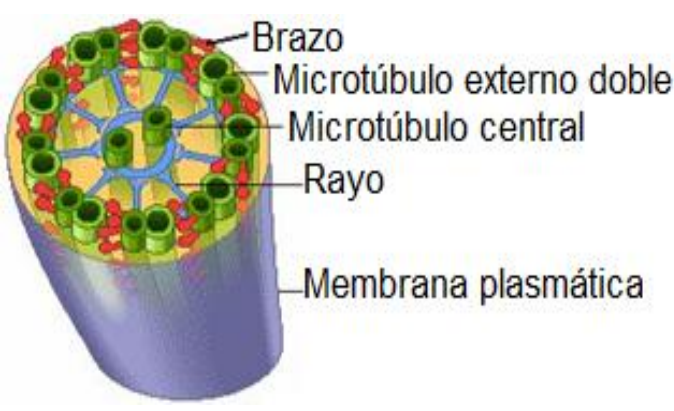

a)

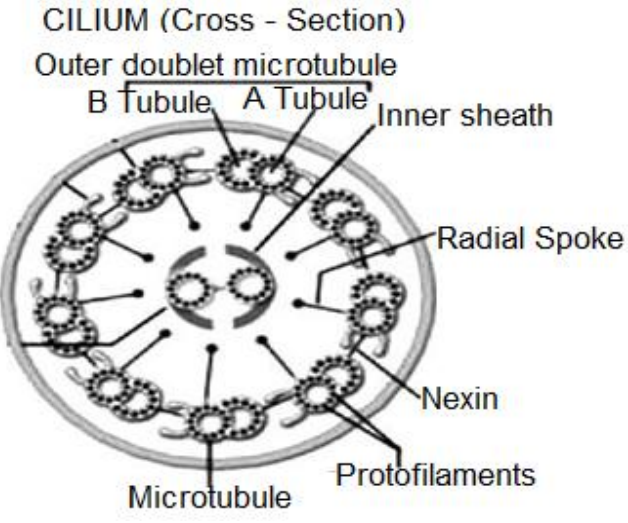

b)

Fig. 2. Estructura de un cilio normal: a) Modelo en perspectiva de la estructura cilíndrica (www.maph49.galeon.com), b) corte transversal de un cilio normal de una célula animal (Brauer, 2003). 
La figura 2 muestra el modelo de la estructura de un cilio normal. En a) se resalta en perspectiva la membrana plasmática, los brazos radiales, los microtúbulos periféricos y centrales; en b) se muestra el modelo del corte transversal del cilio normal. En él se observan los diferentes componentes del axonema ciliar que aparecen revestidos por una extensión de la membrana plasmática celular (MPC). Dentro de esta membrana se incluyen nueve pares de microtúbulos periféricos (MTP) y un par de microtúbulos centrales (PMC), denominada la disposición $9+2$. Los microtúbulos se encuentran a lo largo de todo el citoesqueleto; es un grupo complejo de estructuras citoplasmáticas que interactúan armónicamente constituyendo la base del movimiento ciliar (González, 2007).

Cada MTP está formado por el microtúbulo A (mTA) y el B (mTB). En la parte delantera del mTA hay dos brazos que son las dineínas ciliares (DC). Estas estructuras están formadas por la proteína responsable del movimiento ciliar. Estos brazos se denominan brazo externo e interno. En el mTA también se encuentra un brazo llamado nexina $(\mathrm{N})$ que lo une con el mTB vecino del siguiente par. Esta estructura pasiva aparece cada $86 \mathrm{~nm}$ a lo largo de los microtúbulos (Brauer, 2003). El PMC está formado por dos microtúbulos independientes. Estos microtúbulos están unidos por una estructura pasiva llamada Kinesina (K), envueltos parcialmente por una vaina interna (VI) que aparece cada $14 \mathrm{~nm}$ a lo largo del cilio. Por último aparece una estructura pasiva proteica denominada proyección radial (PR) que sale de cada PMP y se proyecta hacia el PMC a intervalos de $29 \mathrm{~nm}$ (Fajardo, 2003).

Dentro de las funciones de los cilios en los organismos multicelulares está la del movimiento de fluidos (Romero, 2003). Esta función es realizada a partir del movimiento de las diferentes poblaciones de cilios existentes en estos organismos. El movimiento del cilio a su vez está determinado por varios de sus componentes estructurales, entre los que se destacan, los microtúbulos, las dineínas, los puentes de nexina y las proyecciones radiales. Los microtúbulos que forman los pares son organelos inestables ya que pueden ensamblarse y disgregarse rápidamente dependiendo de factores físicos y químicos como temperatura, presión, concentración de iones de calcio, $\mathrm{pH}$ y alcaloides. La dineína es la responsable del deslizamiento de los microtúbulos, dando origen al movimiento y batir armónico de los cilios, mientras que los puentes de nexinas y las proyecciones radiales son las encargadas de restituir el cilio a su posición inicial (Yates, 2007).

La ausencia o deformación de alguna de las proteínas altera la estructura del cilio en forma general haciendo que los mutantes pierdan capacidad de motilidad. Hay varios procesos fisiológicos que se ven afectados por estas alteraciones, presente en mamíferos con dificultades para drenar las secreciones del tracto respiratorio. Esta dificultad es un factor determinante en la patología denominada Disquinesia Ciliar Primaria (DCP), elemento utilizado para el diagnóstico de diferentes enfermedades en mamíferos y en el caso particular de humanos en patologías como el Síndrome de Kartagener (SK), (Fernández, 2011; Kartangener, 1993; Teppa, 2004; Valenzuela, 1980) y el Síndrome de Young (SY) (Chin, 2002), consideradas como Enfermedades Raras (Benavides, 2011).

El procesamiento óptico-digital de imágenes es ampliamente utilizado en el estudio, análisis y caracterización de tejidos biológicos (Herrera, 2008). Los algoritmos y los descriptores utilizados para la extracción de información a partir de imágenes, varían de acuerdo a los objetivos de cada aplicación. En la bibliografía relacionada con el tema, se encuentra que para el estudio de lesiones arteriales se ha utilizado métodos que consisten en aplicar un preprocesamiento de la imagen y posteriormente desarrollar algoritmos de la segmentación de imágenes, dentro de los que se destacan el de Kolmogorov - Smirnov (Rodríguez, 1997). En el estudio de defectos internos de frutos se utiliza el procesamiento de imágenes aplicando algoritmos de segmentación en la imagen de la pulpa, para posteriormente desarrollar operaciones aritméticas y morfológicas que permitan buscar umbrales para detectar daños internos invisibles (Aristizábal, 2006).

De forma general en la caracterización de las estructuras de tejidos biológicos se utilizan algoritmos y descriptores basados en la morfología matemática y la segmentación de imágenes (Madrigal, 2007; Herrera, 2009). Sin embargo, al realizar un balance de las investigaciones en las que se obtienen imágenes de las estructuras ciliares, solo se ha observado el uso del procesamiento óptico-digital para: la obtención de imágenes, la mejora de la calidad de las imágenes, la obtención de estadísticas de diferentes deformaciones celulares vinculadas a patologías estudiadas, etc.; pero no se observa el uso de herramientas de morfología matemática y segmentación en el análisis de estas imágenes (Ferrer, 2009; Esmendi, 2006). Es así que el objetivo de esta investigación es aplicar algoritmos de la morfología matemática y la segmentación en el procesamiento de imágenes del epitelio pulmonar donde están presentes los cilios, que permitan aportar criterios de la deformación estructural del mismo, aspecto que permite diagnosticar deficiencias en la movilidad ciliar.

Atendiendo a esta problemática, es de interés de esta investigación, aplicar el procesamiento óptico digital de imágenes para el estudio morfológico de cilios y en particular de los componentes estructurales asociados al movimiento ciliar. Con la aplicación de ciertos algoritmos a las imágenes digitales, se podrá 
evidenciar la presencia o no de membranas, dineínas, microtúbulos o la alteración según el modelo celular, que permiten caracterizar el corte biológico del tejido de los mamíferos que han sido diagnosticados con este problema ciliar.

\section{MATERIALES Y MÉTODOS}

\section{Diseño de experimento}

Para realizar el estudio morfológico de los cilios, primero se utilizaron modelos de cortes transversales de cilios para establecer los algoritmos necesarios del procesamiento de imágenes para luego aplicarlos en imágenes de las biopsias de mamíferos (Rodríguez, 2007). Las imágenes reales que se utilizaron, son cortes ciliares de biopsias de la mucosa bronquial de dos pacientes caninos. Para obtener las imágenes se sigue el protocolo necesario en la preparación y fijación de las biopsias. Se obtienen cortes transversales ultrafinos de $90 \mathrm{~nm}$ con el ultramicrótomo, contrastadas con acetato de uranilo y citrato de plomo y finalmente son observadas y registradas las imágenes con el microscopio electrónico de transmisión TEM, JEOL JEM 1200EX II (Jurado, 2008). Para el procesamiento de las imágenes y de otros procesamientos estadísticos se utilizaron programas desarrollados para la investigación en lenguaje MATLAB 7.9 (R2009b) (MatWork Inc. USA) y el IMAGEJ.

\section{Metodología}

Para realizar la caracterización morfológica de los cilios se aplica la siguiente metodología: i) Seleccionar imágenes de un cilio normal y determinar qué estructuras del mismo serán estudiadas por el procesamiento óptico digital. Hacer un preprocesado del modelo para el mejoramiento de la imagen; ii) Establecer, desarrollar y aplicar algoritmos de morfología que permitan describir la deformación del cilio a partir del modelo del cilio; y iii) Aplicar los algoritmos y descriptores desarrollados en imágenes de microscopía electrónica de cilios reales, que permitan reconocer, clasificar e interpretar la deformación de los cilios.

A partir de analizar los componentes del modelo cilio normal y fundamentalmente las estructuras relacionadas con la movilidad del mismo, se determina qué algoritmos y descriptores se van a aplicar para valorar: la ausencia de la MPC, la ausencia de algún microtúbulo de los PMP o del PMC y la ausencia de las dineínas, como elementos determinantes en el análisis del buen funcionamiento de los cilios. Esta decisión se basa en que, de los elementos estructurales del cilio que están relacionados con la movilidad del mismo, sólo estos elementos se encontrarán siempre en una imagen de microscopio de un corte transversal del cilio realizado en cualquier plano a lo largo del mismo. Las otras componentes del cilio que participan en su movilidad, son las nexinas y las proyecciones radiales; estas estructuras solo aparecen en determinadas ubicaciones a lo largo del cilio. Por tal motivo la presencia de ellas en el corte transversal del cilio está en dependencia de por donde se realice dicho corte. Esta incertidumbre determina que no se desarrollen los algoritmos y descriptores que valoren la presencia o no en las imágenes de cortes transversales del cilio de estas estructuras. Los algoritmos a aplicar y desarrollar se basan en las herramientas del análisis morfológico y de la segmentación de imágenes. Las funciones relacionadas con estos procedimientos tienen sus fundamentos en la teoría matemática de los conjuntos.

\section{RESULTADOS Y DISCUSION}

Se selecciona como imagen el modelo del cilio normal mostrado en la figura 2 b). Sobre este corte transversal se hace el pre procesamiento de la imagen del cilio para aplicarle los diferentes algoritmos. Este pre procesamiento consiste en mejoras de contrastes, de intensidad, de filtrado de la imagen tratando de mantener definidos los bordes de las estructuras internas. Finalmente se realiza la binarización, inversión y filtrado de la misma (figura 3 ).

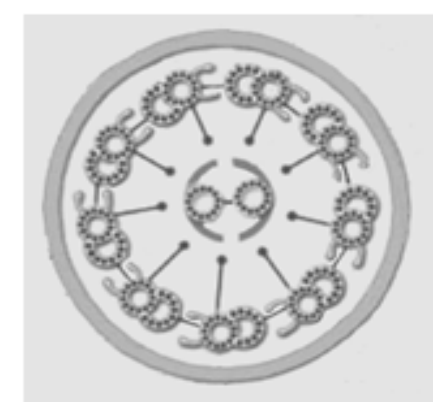

a)

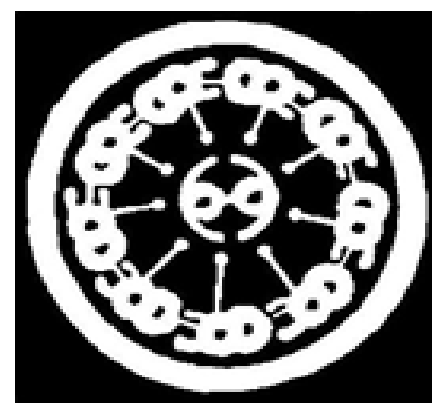

b)

Fig. 3: Modelo del corte transversal de un cilio normal preprocesada: a) filtrada y b) binarizada 


\section{Caracterización de la MPC}

La ausencia de la MPC es el aspecto fundamental a tener en cuenta al analizar la deformación del cilio. Para caracterizar su ausencia se desarrollaron algoritmos que se aplicaron primero en el modelo del cilio. La estrategia seguida consistió en la eliminación de todas las estructuras internas del cilio dejando solo su MPC. A partir de la imagen de la figura 3 (b) se utilizaron funciones de la morfología matemática (shrink, erode y open) y se eliminaron las estructuras internas, dejando solo la membrana (figura 4).

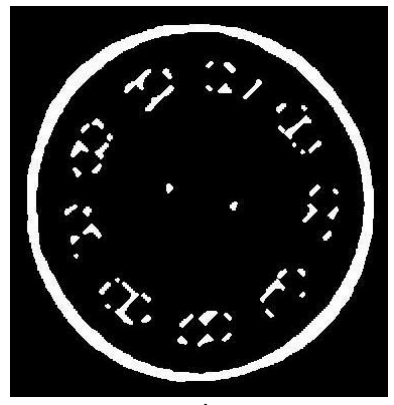

a)

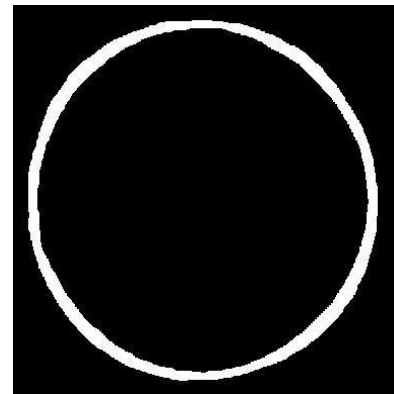

b)

Fig. 4: Procesamiento del modelo del cilio (a) reducción de estructuras (b) membrana sola

Los algoritmos desarrollados para analizar la presencia de la membrana se aplicaron en imágenes obtenidas por microscopía electrónica de los cortes transversales de cilios reales. Al aplicar estos se obtuvo como resultado las imágenes mostradas en la figura 5. La imagen original se preprocesa hasta lograr que las estructuras internas desaparezcan dentro del ruido de alto contraste. Posteriormente se aplican los algoritmos de la morfología matemática y de segmentación (edges, makebinary y open) para transformar y eliminar todos los elementos pequeños de la imagen y lograr que solo se observe la membrana (figura $5 \mathrm{~d}$ ).

Al emplear los algoritmos utilizados anteriormente en imágenes de cilios reales sin membranas plasmáticas (figura 6), se observa la eliminación de todas las estructuras internas y la imagen aparece completamente negra al aplicar las funciones de morfología matemática ya experimentadas.

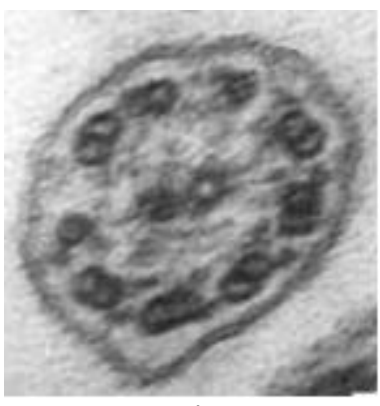

a)

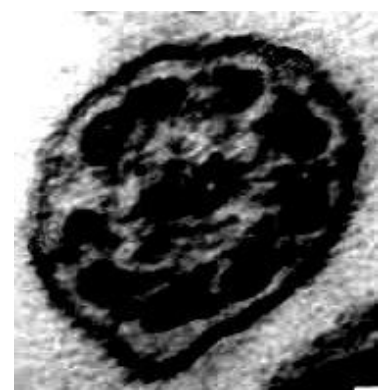

b)

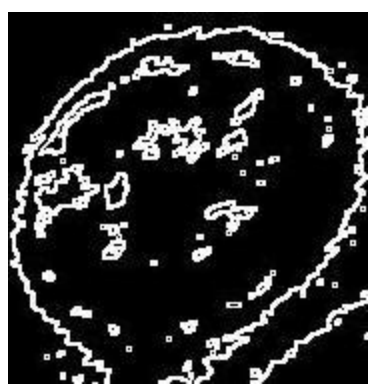

C)

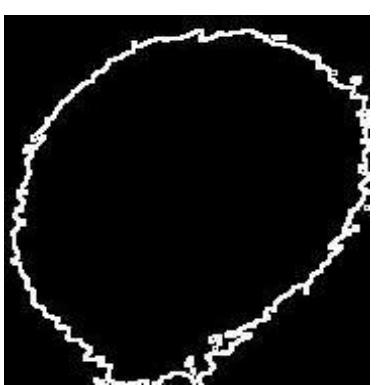

d)

Fig. 5: Corte transversal de un cilio de un mamífero: a) cilio original b) cilio preprocesado, c) cilio aplicando segmentación, d) análisis de la morfología matemática.

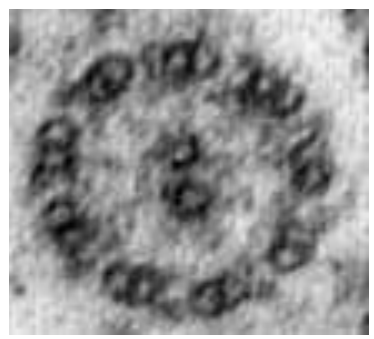

a)

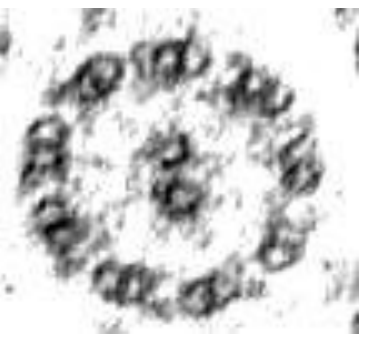

b)

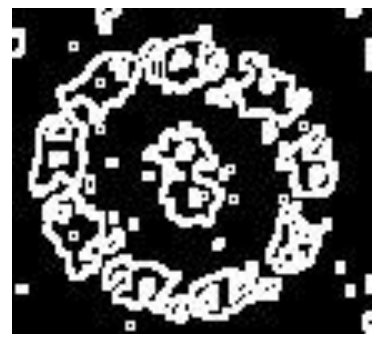

c)

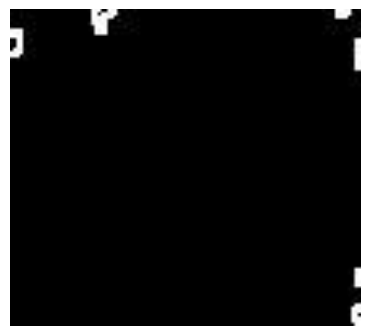

d)

Fig. 6: Cilio sin membrana (a) original, (b) preprocesada, (c) binarizada invertida y (d) aplicada la morfología matemática 


\section{Caracterización de los microtúbulos}

La ausencia de uno de los microtúbulos del cilio se realiza a partir del análisis de la ausencia de alguno de ellos en los PMP y el PMC. En la imagen del modelo ciiar y binarizada, se aplican funciones de la morfología matemática (erosión y apertura) para eliminar las pequeñas estructuras que provocan ruido en la imagen binaria, posteriormente se elimina la membrana hasta lograr separar los pares de microtúbulos del cilio. Un resumen del proceso se puede observar en la figura 7.

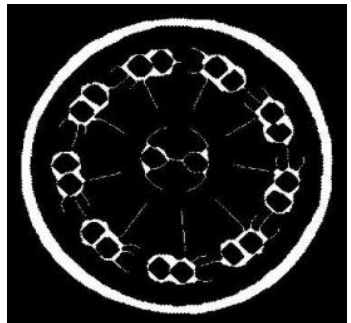

a)

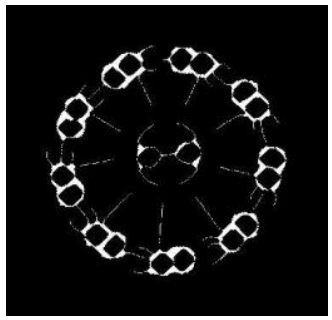

b)

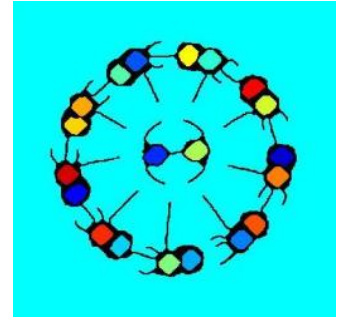

c)

Fig. 7: a) reducción de estructuras b) sin membrana c) enumeración de microtúbulos

Se enumeran los microtúbulos individualizados. Finalmente se cuentan la cantidad que existen, una aritmética elemental permite analizar cuantos hay.

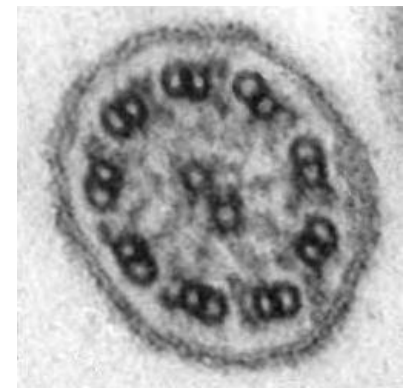

a)

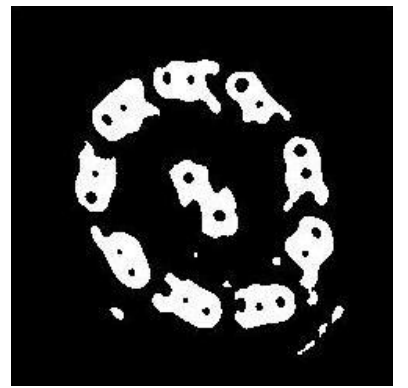

b)

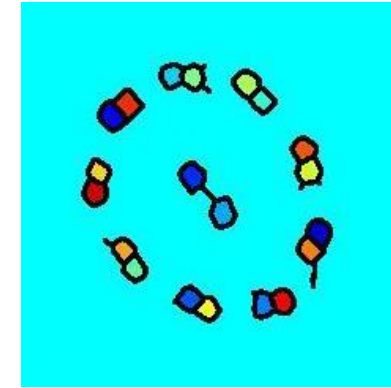

c)

Fig. 8: Corte transversal de cilio de mamífero (a) original y (b) binarizado c) enumeración de microtúbulos

La metodología y algoritmos desarrollados se aplicaron a esta imagen de los cortes transversales de cilios de mamíferos obtenida también por microscopía electrónica. Al aplicar los algoritmos a la figura 8 a) se obtuvo como resultado un cilio con los microtúbulos completos. En este caso particular desde la aplicación de la binarización se eliminó la MPC, lo cual disminuye el tiempo de procesamiento. Finalmente se pasa al conteo de los microtúbulos, según se observa en la figura 8 c).

\section{Caracterización de las dineínas}

Para la caracterización de las dineínas se sigue como estrategia fundamental eliminar las estructuras de los microtúbulos, las estructuras de las nexinas y de las proyecciones radiales. En la figura $8 \mathrm{c}$ ) que ha servido para hacer el conteo de los microtúbulos, también se pueden definir las dineínas. Se observa que los mTA no cuentan con los dos brazos de dineínas. Según el modelo cada uno debería tener dos brazos de dineínas, lo cual permite afirmar que el cilio está alterado. Siendo este factor determinante para afirmar que esta imagen corresponde a una muestra de un tejido con disquinesia ciliar.

Al realizar una valoración general de los resultados obtenidos, se ha podido observar que la aplicación de las metodologías y algoritmos desarrollados a partir de un modelo del cilio, han permitido la caracterización de la estructura interna de los cilios reales, obtenidos por microscopía electrónica (TEM). Al estudiar cada una de las estructuras vinculadas al movimiento ciliar desde las imágenes reales, en algunos casos, no fue necesario aplicar todos los pasos de la metodología, ya que en estas imágenes reales no aparecen de forma definida algunas de las estructuras básicas del cilio. 


\section{CONCLUSIONES}

Utilizando imágenes del modelo de un cilio, se hizo el estudio morfológico, que permitió evidenciar los algoritmos necesarios para evaluar las características de los elementos determinantes de la imagen en la movilidad ciliar, para luego ser aplicados a los cilios reales de mamíferos.

Al aplicar los algoritmos a las imágenes procesadas de los cilios reales, se especificó con certeza la ausencia de los brazos de dineína en unos cortes, ausencia de la membrana plasmática en otros, como factores determinantes para anticipar la disquinesia ciliar.

La aplicación de procesos digitales a imágenes obtenidas por microscopía electrónica (TEM), permitió evaluar, por primera vez, las alteraciones de estructuras de los cilios y a partir de estos resultados, contribuir con esta metodología, al diagnóstico de la disquinesia ciliar en mamíferos.

\section{AGRADECIMIENTOS}

A la Doctora Susana Jurado, Directora del Servicio Central de Microscopía Electrónica, de la Universidad Nacional de la Plata, Argentina y su grupo de investigación por facilitar las imágenes de mamíferos caninos utilizadas en esta investigación.

\section{REFERENCIAS}

Alfonso, J. E., Teoría básica de microscopía de transmisión, 1a Ed.Facultad de Ciencias, Universidad Nacional de Colombia, Sede Bogotá, pp. 17-25, (2010).

Aristizábal, T. I. D., Estudio, aplicación y propuesta de automatización del procesamiento de imágenes por resonancia magnética para la evaluación y detección de defectos internos de calidad en cítricos y melocotones. Tesis de doctorado. Universidad Politécnica de Valencia, Departamento de Mecanización y Tecnología Agraria, (2006).

Barrett, K. E., Ganong Fisiología médica, bases celulares y moleculares de la fisiología médica, 23a. Ed., Editorial Mc. Graw Hill, $34-40,(2010)$.

Benavides, G.M., Rol del médico ante las enfermedades rara, 2(2), Ciencias biomédicas, Cartagena, Colombia, 327-330, (2011).

Brauer, M.M., Viettro L., Aportes de la microscopía electrónica de transmisión al diagnóstico de la disquinesia ciliar (Médica del Uruguay (19), 140-148, (2003).

Chin, G.Y., Karas, M. D.E., Kashgarian, Correlation of presentation and pathologic condition, (2002).

Esmendi, G.K., "Factores de riesgo de mortalidad precoz del trasplante pulmonar", tesis doctoral, Universidad Autónoma de Barcelona, (2006).

Fajardo, D. G., Otorrinolaringología, Intersistemas, Ed. México D.F. , 6-7, (2007).

Fernández, G.S., y otros autores, Síndrome de Kartagener: bases genéticas y hallazgos clínicos, 10 (1), Habanera de Ciencias Médicas, 37-44, (2011).

Ferrer, R.O., Endomicroscopía en Anatomía Patológica: Biopsia Óptica, Rev. Lett. 42(3), Española de Patología, (2009).

González, C., y otros 3 autores, Cultivo primario de células ciliadas de adenoides humanas: Un modelo experimental para evaluar la actividad ciliar vitro (67-2), Otorrinolaringol. Cir. Cabeza Cuello [online]. 2007), [citado-2011-07-05] pp. 99-107.Disponible <http://www.scielo.cl/scielo.php?script=sci_arttext\&pid=S0718-48162007000200002\&lng=es\&nrm=iso>. ISSN 0718-4816. doi: 10.4067/S0718-48162007000200002, (2007).

Gort, H M., Situs Inversus totalis, Ciencias Médicas de Pinar del Río, 14(1), ISSN 1561 - 3194, 250-255, (2010).

Haugland, R., Intracellular Ion Indicators. Fluorescent and Luminiscent Probes for Biological Activity, Edited by W.T. Mason. Academic Press, (1992). 
Herrera, M., Daza J., Análisis de Imágenes utilizando Microscopía confocal, Journal of Science Education, Speciall ssue, Memorias del Congreso Internacional de Educación en Ciencias, 10 años, Cartagena, Colombia, (10) julio 15-18, [ISSN 0124-5481], (2009).

Herrera, M., Daza J., Moreno A., Mavilio A. Caracterización de muestras de materiales biológicos mediante imágenes obtenidas por técnicas interferométricas y de microscopía, en XIV Convención Científica de Ingeniería y Arquitectura, diciembre, La Habana, Cuba, (2008).

Hornef, N., Olbrich H., Horvath J., DNA h5 Mutations are a common cause of primary ciliary dyskinesia with outer dynein arm defects, Am. J. Respir. Crit. Care. Med, $174-180$ (2006).

Jurado, S., Giordano A.L., Diagnóstico de disquinesia ciliar primaria mediante microscopía electrónica en dos pacientes caninos, 17(1), Acta Microscópica, 39-44, (2008).

Kartagener, M.Z. , Pathologic der Bronchiektasien; Bronhiektasiesbei Situs viscerum inversus, Rev. Lett. 83, BeirtKlin. Tuberk, 489-501, (1993).

Madrigal, C., Ramírez J., Diseño de un sistema biométrico de identificación usando sensores capacitivos para huellas dactilares, Facultad de Ingeniería Universidad de Antioquia, Medellín, Colombia, marzo, (30), [ISSN 0120 - 6230], 21-32 (2007).

Morán, D.T., Powley C.J., Biological specimen preparation for correlative light and electron microscopy, Instrumentation and methods, Ed. M. A. Hayat, Academic Press, New York, 1-22, (1987).

Pertuz, S.D. Sistema de adquisición automática de imágenes para microscopio óptico, (22), Barranquilla July - Dec., Print version ISSN 0122-346, (2007).

Rodríguez, R., y otros 4 autores, Método de segmentación de imagen aplicados a las lesiones arteriales I. Comparación, Cubana de Investigaciones Biomédica, Ciudad de La Habana, 16(1) ene-jun, [versión impresa ISSN 0864-0300], (1997).

Rodríguez, Y., Ética de la investigación en modelos animales de enfermedades humanas, Acta bioeth, 13(1), [on line] [ISSN 1726-569X], [doi: 10.4067/S1726-569X 2007000100004], 25-40, (2007).

Romero de P G.,Microscopía Electrónica de transmisión (MET)., Área Biomédica, Teoría y Práctica, Academia Colombiana de Ciencias Exactas, (Editorial Guadalupe, Colombia, [ISBN 9589205 - 38-5], (2003)

Tabata, Y., Sonodynamic Effect of Polyethylene glycol-conjugated Fullerene on Tumor en Osawa, Prespectives in Fullerenes Nanothechnology, Kluwer Academic Publishers. (2002).

Teknos, T.N., Metson R., Chasse T., New developments in the diagnostic of Kartagener's syndrome (166), Otolaryngol Head Neck Surg,, 68-74, (1997).

Teppa, G. A.D., Palacios T A., Evaluación actual de la infertilidad masculina, Revista Investigación clínica, Departamento de Andrología, Clínica el Ávila, Caracas, Maracaibo Rev. Lett. 45-4, ISSN 0535 - 5133, (2004).

Valenzuela, J., Medina S., Síndrome de Kartagener en el niño, Revista chilena de Pediatría, Santiago de Chile, 51(5), [ISSN 0370-4106], (1980).

Villaveces, J.J.. Tecnología y Sociedad: un contrapunto armónico, Revista de Estudios Sociales, de la Universidad de los Andes, Bogotá, Colombia , (2005).

Yates, R.H., Estructura, movimiento y patología de los cilios respiratorios, Expresiones Médicas, Instituto de Ciencias biomédicas, Universidad Autónoma, ciudad Juárez, (3) enero - junio, 30 - 35, (2007). 